\title{
Estudo sobre a Orientação Vocacional e Profissional - Escolhas
}

\author{
Laura Silva \\ Universidade Lusófona de Humanidades e Tecnologias - Lisboa - Portugal
}

\begin{abstract}
Resumo
A questão "o que queres ser quando fores grande?" impulsionou o estudo que se descreve. Este teve por finalidade investigar a importância atribuída à orientação escolar, vocacional e profissional por parte dos estudantes. Participaram neste estudo 114 estudantes a frequentar o ensino básico e secundário, tendo usufruído dos Serviços de Psicologia e Orientação (SPO) no último ano letivo. Os dados foram recolhidos através do questionário "Orientação Vocacional". Os resultados apontaram que a maioria dos estudantes considera que os SPO compreendem as suas necessidades, no entanto, $39,5 \%$ considera que as suas dúvidas não ficaram esclarecidas. Assim, é fundamental perceber como os estudantes são ajudados no seu processo de decisão vocacional e em que medida são orientados para o seu percurso futuro.
\end{abstract}

Palavras-chave: Psicologia escolar; orientação vocacional; orientação profissional.

\section{Study on Vocational Guidance and Professional - Choices}

\begin{abstract}
The question "what do you want to be when you grow up?" Spurred the study described. This research aimed to investigate the importance given to education, vocational and professional guidance by the students. The sample consisted of 114 students attending primary and secondary schools, having enjoyed the Psychology and Guidance Services (SPO) in the last school year. Data were collected through the questionnaire "Vocational Guidance". The results showed that most students think that the SPO understand their needs, however, 39.5\% consider that their questions were not answered. Thus, it is essential to understand how the students are helped in their vocational decision-making and to what extent are geared to your future course.
\end{abstract}

Keywords: School psychology; vocational orientation; professional orientation.

\section{Estudio sobre la Orientación Vocacional y Profesional - Escojas}

\section{Resumen}

La cuestión “¿lo qué quieres ser cuando seas grande?” impulsó el estudio que se describe. Éste tuvo por finalidad investigar la importancia atribuida a la orientación escolar, vocacional y profesional por parte de los estudiantes. Participaron en este estudio 114 estudiantes a frecuentar la enseñanza básica y secundaria, teniendo aprovechado de los Servicios de Psicología y Orientación (SPO) en el último año lectivo. Se recolectaron los datos por intermedio del cuestionario "Orientación Vocacional". Los resultados apuntaron que la mayoría de los estudiantes considera que los SPO comprenden sus necesidades, sin embargo, el 39,5\% considera que sus dudas no quedaron aclaradas. Así, es fundamental percibir como los estudiantes son ayudados en su proceso de decisión vocacional y en qué medida son orientados para su camino futuro.

Palabras clave: Psicología escolar; orientación vocacional; orientación profesional. 


\section{Introdução}

O decreto-lei 190/91 veio institucionalizar a Orientação Vocacional (OV) no sistema público de ensino, no quadro formal da criação dos SPO, mas em Portugal o interesse pela OV não é recente. Prova disso é a criação do Instituto de OV na década de 1920. Importa ainda referir no âmbito do Ministério do Trabalho a existência de estruturas dedicadas à OV com uma história mais antiga que a do Ministério da Educação (Leão, 2007).

Os SPO estão implementados nos estabelecimentos de educação Portugueses, tendo três domínios considerados para a sua intervenção: apoio psicopedagógico a estudantes e a professores; apoio ao desenvolvimento do sistema de relações da comunidade educativa e orientação escolar e profissional. A salientar, o planear e executar atividades de orientação escolar e profissional através de programas e ações de aconselhamento a nível individual e de grupo, colaborar com outros serviços, nomeadamente no apoio à celebração de protocolos, tendo em vista a organização de informação e orientação profissional, desenvolver ações de informação e sensibilização dos pais e da comunidade em geral no que respeita à problemática que as opções escolares e profissionais envolvem (Ministério da Educação, 2012).

No panorama atual é importante perceber o papel da escola na orientação escolar e profissional dos seus estudantes. É a partir das escolhas profissionais que o estudante faz a transição para o mercado de trabalho. Na atualidade, o mercado de trabalho está cada vez mais competitivo, ocorreram demasiadas mudanças na economia mundial e as empresas são cada vez mais exigentes com os seus trabaIhadores. As transformações ocorridas ao nível do trabalho têm reflexos evidentes nos sistemas de educação, formação e emprego - materializadas por exemplo, no novo paradigma da educação e formação ao longo da vida (Leão, 2007).

A este nível, Carvalho (2012) no seu estudo acerca da OV em Portugal, refere a importância da promoção de competências de gestão na carreira e apoio na transição para o mercado de trabalho. Realizar uma opção profissional e escolar torna-se uma circunstância bastante complexa que requer um conhecimento aprofundado não apenas das áreas específicas mas também de si próprio. A escolha vocacional acontece num período conturbado da vida do estudante, período de crises, conflitos, transição, adaptação, ajustamentos e mudanças, próprios do desenvolvimento do indivíduo na adolescência (Sprinthall \& Collins, 1995). Deste modo, considerando a importância do papel dos SPO temos por principal objetivo de estudo obter conhecimento sobre a atuação dos SPO e de que forma estes correspondem às necessidades apresentadas pelo estudante.

Em Portugal, o Ministério da Educação é um dos organismos com mais responsabilidades, devendo fornecer Serviços de Psicologia e Orientação nas escolas públicas. Visando a estrutura do sistema educativo em Portugal que obriga os estudantes no fim do ensino básico a tomarem uma decisão com implicações no seu futuro trajeto ao nível de educação e formação. $\mathrm{O} 9^{\circ}$ ano de escolaridade é aquele onde se verifica uma oferta múltipla ao nível escolar, bem como, ofertas de programas de intervenção vocacional (Königstedt, 2011).

Logo, para muitos jovens a chegada ao final do $9^{\circ}$ ano gera com frequência stress e desperta a atenção de pais e encarregados de educação (Silva, Paixão, \& Albuquerque, 2007). Os pais tornam-se importantes no apoio da tomada de decisões (Otto, 2000), tendendo os jovens, nesta fase que implica uma primeira decisão, a escutarem e solicitar o envolvimento parental. Após esta decisão, tomada habitualmente no final do $9^{\circ}$ ano, os jovens estudantes apoiam-se nos pais para a implementação dessa escolha (Königstedt, 2011). Os pais dos dias de hoje, cada vez mais esclarecidos e preocupados com as alterações e exigências no acesso ao mundo laboral, mostram também uma crescente preocupação e envolvem-se mais neste processo. Tais factos permitem que os pais se tornem parceiros envolvidos e esclarecidos nesta fase da vida dos estudantes.

É também relevante que o desenvolvimento e a organização da oferta das intervenções vocacionais em contexto escolar sejam uma prioridade definida. Sem dúvida que a consulta de psicologia vocacional (estruturada e breve) tem mérito incontestável mas apresentando, no entanto, alguns inconvenientes (Königstedt, 2011). Nomeadamente existe risco acrescido de se excluir parte da população escolar que possa estar menos sensível acerca da importância de tal (Königstedt \& Taveira, 2010). Por outro lado, uma maior oferta de atividades extracurriculares faz com que a comunidade escolar tenha uma perceção errada, confundindo-se muitas vezes, e não se separando o desenvolvimento vocacional e o processo educativo a um nível mais global do estudante (Taveira, 2005).

Neste sentido, torna-se possível contribuir para uma consciencialização precoce dos jovens relativamente à instrumentalidade das aprendizagens escolares para o seu futuro percurso formativo e profissional (Schultheiss, 2005), como também pode ser útil no combate aos estereótipos de género na escolha da profissão (Araújo \& Taveira, 2006).

O psicólogo deverá ter um papel relevante na orientação e monitorização dos professores relativamente à forma mais adequada de tornar estas atividades significativas para os jovens, no sentido do seu enriquecimento pessoal (Königstedt, 2011).

Os professores podem assumir um papel importante não somente na promoção de experiências do contexto real de trabalho como desempenham um papel relevante nas escolhas vocacionais dos jovens, já que exercem a sua influência tanto na relação direta com os alunos, como indiretamente no seu contacto com a família (Carvalho \& Taveira, 2010). Uma dificuldade relaciona-se certamente com a colaboração de docentes e psicólogos em sala de aula, uma vez que os diferentes papéis correm o risco de serem diluídos (Whiston \& Aricak, 2008). Uma possível linha de investigação futura poderá analisar as perceções de docentes e psicólogos relativamente à sua colaboração em tais projetos, focando questões como a partilha do poder e a importância da dimensão relacional para o sucesso do projeto (Königstedt, 2011). 
Um estudo levado a cabo pelo Conselho Nacional de Educação (CNE, 2011) sobre Orientação e Formação realizou-se numa escola secundária da rede pública de Lisboa que dispõe de uma experiência cimentada no domínio da orientação vocacional. Pretendeu-se perceber como os estudantes são ajudados no seu processo de decisão vocacional, nomeadamente, como contribuem as instâncias em causa (SPO e currículo) para a exploração do autoconceito, das alternativas de formação, do mundo das profissões e do trabalho e para a definição e decisão sobre o seu projeto vocacional. Interessou-nos perceber, também, como se processa o apoio aos jovens na aquisição de conhecimentos e de competências de vida, especialmente facilitadoras das tarefas vocacionais.

Os técnicos que aceitaram responder ao questionário referiram como principais aspetos positivos: universalidade e gratuitidade da OV; localização do serviço nas escolas e sua consequente acessibilidade aos estudantes e famílias; localização do serviço nas escolas e consequente potenciação de práticas de articulação com a escola, seus profissionais, estruturas pedagógicas e currículo; qualidade e flexibilidade na resposta em OV tendo em conta a natureza dos destinatários e os constrangimentos dos serviços; capacitação e envolvimento das famílias na OV; respeito pela autonomia profissional; reconhecimento da natureza especializada do aconselhamento vocacional; facilidade de acesso à informação sobre as alternativas de formação. Como aspetos negativos os mesmos técnicos salientaram: indefinição da política geral para o sector; política de recrutamento e emprego pouco clara e errante; elevado rácio psicólogo/alunos em muitos serviços; elevada dispersão geográfica do atendimento em muitos serviços; ausência de incentivo e apoio à cooperação entre SPO e mesmo preocupante retrocesso em tal orientação; ausência de incentivo e apoio à cooperação entre SPO e outros serviços de orientação destinados a outros públicos, e também outras estruturas da comunidade, com especial referência às instituições de ensino superior do sector; ausência de incentivo e apoio à formação contínua e à supervisão; dificuldades várias no domínio da informação sobre as formações, nomeadamente sobre a atualidade da mesma, uniformidade do suporte, entre outros; insuficiências graves no domínio da informação sobre a economia, o trabalho, o emprego, absorção das qualificações, entre outros; recursos técnicos de avaliação e intervenção pouco atualizados, adaptados e aferidos, quando é o caso; insuficiente proximidade da administração relativamente aos profissionais e aos serviços, e as consequências nefastas de tal prática no efetivo conhecimento e monitorização do que se passa no terreno (CNE, 2011).

Leão (2007) sugere que sejamos mais ambiciosos e que alarguemos a questão vocacional à própria cidadania, pois considera que não nos envolvemos na comunidade. Aconselha que se fale antes em biografia, implicando o envolvimento autobiográfico dos jovens e as implicações para a cidadania. Em vez de se procurar através da orientação vocacional a descoberta de uma vocação algures escondida.

\section{Método}

\section{Participantes}

Fizeram parte deste estudo estudantes a frequentar o ensino básico $\left(9^{\circ}\right.$ ano $)$ e secundário $\left(10^{\circ}, 11^{\circ}\right.$ e $12^{\circ}$ ano), tendo usufruído dos SPO no último ano letivo. Distribuindo-se por $9^{\circ}$ ano (14\%), $10^{\circ}$ ano $(52.6 \%), 11^{\circ}$ ano $(23.7 \%)$ e $12^{\circ}$ ano (9.6\%). A amostra é constituída por 114 participantes, sendo 72 do género feminino e por 42 participantes do género masculino, correspondendo, respetivamente, do total da amostra. Os estudantes frequentam escolas do ensino básico e secundário do distrito do Porto.

\section{Instrumentos}

Foi construído um questionário em versão experimental, "A orientação vocacional", tendo como objetivo explorar as expectativas do estudante face à orientação vocacional. Procurou-se perceber se o desenvolvimento do percurso escolar consistia numa preocupação dos estudantes face ao seu percurso escolar e profissional, bem como as decisões a tomar se tiveram em conta o processo de avaliação pelo qual passaram nos SPO.

Este questionário é composto por 27 itens. Os itens da primeira parte do questionário encontram-se numa escala tipo Likert (Mau, Insatisfatório, Satisfatório, Bom, Excelente). Os itens são compostos por questões relacionadas com: Simpatia e qualidade do atendimento prestado; Horário do atendimento; Eficiência e eficácia; Utilidade; Esclarecimento explícito; Compreensão das suas necessidades; Rigor e clareza das informações prestadas; Capacidade de aconseIhamento; Tempo de resposta.

A segunda parte do questionário aborda questões sobre o SPO e em que medida este foi ao encontro do que o estudante esperava, sendo também as respostas para os itens numa escala tipo Likert (Discordo totalmente. Discordo. Concordo. Concordo bastante. Concordo completamente). Os itens eram compostos por questões relacionadas com: Reconhecimento e importância dos SPO; Esclarecimento de dúvidas, capacidades e competências; Conhecimento sobre tipos de cursos e de profissões; esclarecimento das relações entre formações, profissões e emprego; Natureza do mercado de trabalho; Satisfação com abordagem alternativa ao ensino superior; Esclarecimento sobre os cursos profissionais; Ações de sensibilização sobre a temática; entrega de relatório escrito com os resultados obtidos.

\section{Procedimento}

Foram selecionadas aleatoriamente quatro escolas do norte do país onde se realizam OV através dos SPO. Após esta seleção, o primeiro contacto deu-se via telefone com vista a averiguar a recetividade das escolas em participar na 
investigação. Face a uma resposta positiva procedeu-se a um segundo contacto com as escolas, no sentido de explicar os objetivos do estudo. Nos casos em que as escolas se mostraram disponíveis foi agendada a administração dos questionários aos alunos. Os participantes foram previamente informados sobre os objetivos do estudo, tendo sido questionados sobre a possibilidade de participação, bem como garantida a confidencialidade e o anonimato das suas respostas. O tempo de aplicação foi de cerca de cinco minutos. Os questionários foram entregues a professores, diretores de turma, estudantes e de forma aleatória, pretendendo-se tornar a amostra o mais significativa possível (Quivy \& Campenhoudt, 2003). Diga-se que foram entregues 147 questionários, tendo sido devolvidos 114 preenchidos.

\section{Tratamento dos dados}

Os dados foram analisados segundo uma metodologia quantitativa. Os dados foram introduzidos, tratados e analisados, com recurso ao programa estatístico SPSS versão 18.0 (Statistical Package for the Social Sciences). Neste trabalho recorreu-se, essencialmente, a dois procedimentos estatísticos, sendo eles as análises de frequências e percentagens e, para comparação de grupos, o teste Mann-Whitney. A adoção de um teste não-paramétrico para a comparação de grupos deve-se ao facto de os dados não seguirem uma distribuição normal.

Uma das limitações no tratamento dos dados foi que o questionário é composto por duas questões abertas; no entanto, não nos foi possível fazer o tratamento estatístico nesta fase do estudo.

\section{Resultados}

A apresentação dos resultados obtidos tem por base os objetivos que orientaram este estudo focando as temáticas nucleares: o grau de satisfação em relação aos SPO e expectativas face às escolhas escolares e profissionais.

Recorreu-se ao teste Mann-Whitney para realizar a comparação dos indivíduos do sexo masculino e feminino nas respostas ao questionário sobre os SPO, uma vez que os dados não seguem uma distribuição normal. Apesar de estar muito próximo da significância estatística ( $p=.056)$, não se verificam diferenças estatisticamente significativas $(U=1187.0, p>.05)$ entre os indivíduos do sexo masculino (Rank Médio $=65.24)$ e os indivíduos do sexo feminino (Rank Médio $=52.99$ ) ao nível da classificação do SPO. Assim, os resultados apontam para a ausência de diferenças significativas relativamente à classificação dos SPO tendo por base o género.

No que diz respeito ao reconhecimento da importância do SPO verifica-se que $5.3 \%$ da amostra discorda, $28.1 \%$ concorda, $53.5 \%$ concorda bastante e $13.2 \%$ concorda completamente. Estes resultados expressam significativamente a opinião dos estudantes sobre a importância dos SPO, já que aproximadamente 95\% reconhece a sua relevância. No item "Ficou esclarecido acerca das dúvidas que tinha enquanto estudante", verifica-se $4.4 \%$ da amostra discorda totalmente, $35.1 \%$ discorda, $42.1 \%$ concorda, $15.8 \%$ concorda bastante e $2.6 \%$ concorda completamente. Deve-se reter nestes resultados a percentagem de estudantes, 39,5\%, que consideram não ter ficado esclarecidos.

Sobre a questão "A orientação foi-lhe útil no esclarecimento das relações entre formações, profissões e emprego", verifica-se que $9.6 \%$ da amostra discorda totalmente, $46.5 \%$ discorda, 30.7\% concorda, 9.6\% concorda bastante e $3.5 \%$ concorda completamente. Deve-se salientar que $56.1 \%$ dos estudantes não considerou a orientação útil no esclarecimento das relações entre formações, profissões e emprego.

Consideram ainda para o item "A orientação foi esclarecedora acerca da natureza do mercado de trabalho e sobre a importância de levar em consideração esse mesmo mercado aquando da tomada de decisões escolares", 58,8\% dos estudantes que não ficaram esclarecidos nos SPO sobre esta questão. No item "Foi-Ihe entregue relatório escrito dos resultados obtidos", 64,9\% dos alunos não obtiveram relatório escrito sobre os resultados da avaliação que lhes foi realizada no âmbito da escolha escolar e profissional.

Como principais aspetos positivos referidos pelos estudantes devemos salientar que uma percentagem de $61,4 \%$ dos estudantes considera que os SPO compreendem as suas necessidades. De reter ainda a percentagem de $60,5 \%$ dos estudantes que viram as suas dúvidas esclarecidas quando recorreram aos SPO.

Os principais aspetos negativos referidos pelos estudantes prendem-se com o tempo de resposta por parte do SPO sendo que $69,3 \%$ considera mau/insatisfatório o tempo de resposta. Saliente-se também uma percentagem de estudantes insatisfeitos com os esclarecimentos relacionados com as alternativas ao ensino superior que se situa em $60,5 \%$.

Ao realizarmos a comparação entre os indivíduos do sexo masculino e do sexo feminino ao nível do grau de satisfação com o SPO verificamos que, apesar de estar muito próximo da significância estatística ( $p=.056)$, não se revelam diferenças estatisticamente significativas $(U=1187.0, p>.05)$ entre os indivíduos do sexo masculino (Rank Médio $=65.24)$ e os indivíduos do sexo feminino (Rank Médio $=52.99$ ). Por sua vez, a comparação entre ambos os sexos ao nível das expectativas em relação ao SPO revelou a existência de diferenças estatisticamente significativas $(U=1174.5, p<.05)$, sendo que os indivíduos do sexo masculino (Rank Médio $=65.54$ ) apresentam expectativas mais elevadas em relação ao SPO do que os indivíduos do sexo feminino (Rank Médio = 52.81).

\section{Discussão}

Denota-se que existe um rácio muito baixo de técnicos para o número de estudantes, evidenciando a falta de técnicos nos SPO. O papel da escola é proporcionar respostas e orientações aos seus estudantes, mas tal torna-se 
humanamente impossível devido à falta de psicólogos em contexto escolar, o que também foi evidente no estudo levado a cabo em 2011 pelo Conselho Nacional de Educação.

Uma percentagem significativa dos estudantes $(61,4 \%)$ não fez a escolha do seu percurso escolar com base nos resultados obtidos na avaliação. De facto, CarvaIho (2012) refere que abordar as necessidades dos alunos implica perspetivar para além de um quadro geral, composto pela maioria dos estudantes que pretende ingressar no ensino superior, no seguimento do ensino secundário. A autora considera a necessidade de se ter em conta a ampla variedade e flexibilidade dos percursos secundários, para que a OV corresponda às necessidades dos alunos.

Saliente-se ainda que $64,9 \%$ dos estudantes não obtiveram um relatório escrito com os resultados dessa orientação. Poderemos sugerir um estudo que analise se existe uma correlação entre as escolhas escolares e a obtenção ou não de um relatório escrito pelos SPO, podendo analisar-se dois grupos comparativamente.

Um aspecto em comum com o estudo desenvolvido em 2011, prende-se com a falta de uma política geral para o setor, ou seja, em cada escola a orientação escolar e profissional é realizada de forma diferente. Assim, seria útil para uma prática mais efetiva que existisse uma política geral para o setor, bem como uma divulgação por parte dos SPO da forma de atuação destes, podendo evitar-se assim, erros ou modelos que se revelem menos efetivos. Aspeto este salientado também num estudo anterior levado a cabo por Leão (2007) o qual refere que em cada legislatura tem-se imposto a criatividade, novos materiais ou a ausência destes, sem qualquer avaliação da eficácia dos que foram produzidos anteriormente e onde Ministério da Educação e Ministério do Trabalho tem atuado na maior parte das situações em perfeita descoordenação.

O estudo desenvolvido em 2011 pelo Conselho Nacional de Educação remete para a existência de insuficiências graves no domínio da informação sobre a economia, o trabalho, o emprego, absorção das qualificações, entre outros. Também verificamos que uma percentagem significativa $(39,5 \%)$ de estudantes considera não ter ficado esclarecida sobre as questões em causa.

Carvalho (2012) refere neste contexto a importância de avaliar os programas e as intervenções, para que estes possam ser reformulados e melhorados em prol de uma intervenção cada vez mais capaz de satisfazer as necessidades dos alunos. A este nível refere como ingredientes críticos o papel do psicólogo escolar no reforço da rede de suporte do aluno e alargar a exploração profissional e da carreira ao mercado de trabalho (Carvalho, 2012).

Um estudo recente de Königstedt (2011) sugere que os programas de intervenção que assumam um caráter promocional e multifacetado podem ser um veículo potencial no desenvolvimento vocacional dos jovens. Assim como, seria vantajoso a criação de uma estrutura de apoio quanto à realização de contactos com empresas, entidades e instituições para o desenvolvimento de projetos de exploração em contexto real de trabalho (Königstedt, 2011).

\section{Considerações Finais}

Esta investigação possibilitou a realização de um estudo sobre a situação da orientação escolar e profissional, que embora não seja suficientemente representativo fornece indicadores para estudos posteriores. A escola do século $\mathrm{XXI}$ deve preparar o estudante para o mercado de trabalho tendo sempre em conta a sua condição humana. O jovem da escola pública espera auxílio por parte dos SPO em relação à escolha académica/ inserção no mercado de trabalho.

A orientação escolar deve-se preocupar em auxiliar o estudante no planeamento do seu projeto de vida, criando alternativas ao seu papel tradicional de somente orientar jovens para a escolha de um curso superior. As abordagens devem possibilitar maior informação profissional e escolar, sem restringir as profissões de nível superior.

É esperado que a orientação escolar se possa tornar uma prática mais global. A orientação escolar e profissional é pois, um processo de ajuda, de carácter mediador e cooperativo, entre o profissional preparado teoricamente e tecnicamente e um sujeito, ou grupo de sujeitos, que usufruem deste auxilio na elaboração e construção do seu projeto de vida (conhecimento do seu processo de escolha, autoconhecimento, conhecimento do mundo de trabalho, entre outros aspetos).

A orientação escolar e profissional poderia ser mais útil, efetiva e eficaz caso os SPO trabalhassem de acordo com uma política geral para este setor, sendo estes serviços dotados de meios técnicos e humanos que se revelassem os mais eficientes possíveis, verifica-se ainda que uma articulação entre ME e MT poderia ser uma mais-valia para a prática da orientação escolar e profissional.

\section{Implicações Futuras}

Da visão geral obtida com esta investigação, emerge o impacto que a orientação escolar e profissional poderá ter na formação/percurso escolhido pelo estudante. Segundo Campos (1992), não é recorrendo ao dicionário de palavras e alinhando uma série delas que se produzem frases significativas; também não é recorrendo ao catálogo das atividades e alinhando uma série delas, ao longo de semanas, que é legítimo esperar algo de consequente. Num e noutro caso, têm de estar subjacentes regras de produção quer seja de frases com sentido quer seja de uma intervenção de orientação significativa para as pessoas.

$\mathrm{Na}$ atualidade, com mercados de trabalho extremamente exigentes, elevadas taxas de desemprego, fenómenos de emigração, entre outros fatores, são aspetos para os quais o estudante deve ser alertado, auxiliado, encaminhado em todo o seu percurso escolar. Assim, os SPO podem em conjunto ajudar o estudante a traçar o seu percurso, podendo este ser o mais bem-sucedido possível.

Será positivo o estabelecimento de projetos e/ou parcerias com elementos da comunidade para poder criar uma estrutura financeira de apoio que contribua para a não 
limitação dos projetos de exploração dos jovens oriundos de famílias com menores recursos económicos, pois os jovens não exploraram todos ao mesmo nível quando chegam à escola (Sobral, Gonçalves, \& Coimbra, 2009).

Em suma, as opiniões manifestadas pelos estudantes são reveladoras de um grupo preocupado com o seu futuro, querendo decifrar as suas potencialidades, são capazes de contribuir quando questionados e dispostos a superar dificuldades e obstáculos com a ajuda dos técnicos, nos quais depositam confiança e muitas vezes esperança.

Consideramos importante e com implicações futuras a investigação junto de estudantes e técnicos de que forma é realizada a orientação escolar e possibilidade desta corresponder mais às expectativas do estudante, tornando-se esta prática mais efetiva e indo ao encontro das expectativas formuladas pelos estudantes.

\section{Referências}

Araújo, A., \& Taveira, M. C. (2006). Activação do desenvolvimento vocacional na infância: O papel promotor dos pais e professores. Em J. Tavares, A. Pereira, C. Fernandes, \& S. Monteiro (Orgs.), Actas do simpósio internacional: Activação do desenvolvimento psicológico. Aveiro, Portugal: Universidade de Aveiro.

Campos, B. P. (1992). A informação na orientação profissional. Cadernos de Consulta Psicológica, 8, 5-16.

Carvalho, M. S. (2012). A implementação de decisões vocacionais no ensino secundário: contributos para a construção de um modelo de intervenção. Dissertação de Doutoramento. Universidade do Minho, Braga, Portugal: Escola de Psicologia.

Carvalho, M., \& Taveira, M. C. (2010). O papel dos pais na execução de planos de carreira no Ensino Secundário: Perspectivas de pais e de estudantes. Análise Psicológica, 2 (28), 333-341.

Conselho Nacional de Educação [CNE] (2011). Estado da Educação 2011. A Qualificação dos Portugueses.

Königstedt, M., \& Taveira, M. C. (2010). Exploração vocacional em adolescentes: avaliação de uma intervenção em classe. Paideia, 20 (47), 303-312.
Königstedt, M. (2011). Intervenção Vocacional em Contexto Escolar. Avaliação de um programa longo em classe com adolescentes. Universidade do Minho: Braga.

Leão, A. P. (2007). A promoção do desenvolvimento vocacional em contexto escolar: O(s) tempo(s) e o(s) modo(s). Revista Portuguesa de Investigação Educacional, 5, 63-78.

Otto, L. B. (2000). Youth Perspectives on Parental Career Influence. Journal of Career Development, 27 (2), 111-118.

Quivy, R., \& Campenhoudt, L. (2003). Manual de Investigação em Ciências Sociais ( $3^{\mathrm{a}}$ ed.). Lisboa: Gradiva.

Schultheiss, D. E. P. (2005). Elementary Career Intervention Programs: Social Action Initiatives. Journal of Career Development, 31(3), 185-194.

Silva, J. T., Paixão, M. P., \& Albuquerque, M. (2007). Relationship between locus of control, causal attributions, and career decision making self-efficacy with career decision difficulties. Poster apresentado no 10 European Congress of Psychology, Praga

Sobral, J. M., Gonçalves, C. M., \& Coimbra, J. L. (2009). A influência da situação profissional parental no desenvolvimento vocacional dos adolescentes. Revista Brasileira de Orientação Profissional, 10 (1), 11-22.

Sprinthall, N., \& Collins, W. A. (1995). Adolescent psychology: A developmental view. New-York: McGraw-Hill.

Taveira, M. C. (2005). Comportamento e desenvolvimento vocacional na adolescência. Em M. C. Taveira (Org.), Psicologia Escolar: Uma Proposta Científico - Pedagógica. Coimbra: Quarteto.

Whiston, S. C., \& Aricak, O. (2008). Development and initial investigation of the school counseling program evaluation scale. Professional School Counseling, 11(4), 253-261.

\section{Sobre a autora}

Laura Silva (psicologialaurasilva@gmail.com)

Psicóloga, formadora, universidade lusófona de humanidades e tecnologias, Lisboa 